\title{
Computer acceptance of older adults
}

\author{
Sibylle Nägle* and Ludger Schmidt \\ Human-Machine Systems Engineering, University of Kassel, Mönchebergstraße 7, 34125 Kassel, Germany
}

\begin{abstract}
Even though computers play a massive role in everyday life of modern societies, older adults, and especially older women, are less likely to use a computer, and they perform fewer activities on it than younger adults. To get a better understanding of the factors affecting older adults' intention towards and usage of computers, the Unified Theory of Acceptance and Usage of Technology (UTAUT) was applied as part of a more extensive study with 52 users and non-users of computers, ranging in age from 50 to 90 years. The model covers various aspects of computer usage in old age via four key constructs, namely performance expectancy, effort expectancy, social influences, and facilitating conditions, as well as the variables gender, age, experience, and voluntariness it. Interestingly, next to performance expectancy, facilitating conditions showed the strongest correlation with use as well as with intention. Effort expectancy showed no significant correlation with the intention of older adults to use a computer.
\end{abstract}

Keywords: Computer usage, elderly computer users, UTAUT, acceptance model

\section{Introduction}

Information and Communication Technology (ICT) became an ever-important factor in recent years. In 2000, the General Assembly of the United Nations announced in its Millennium Declaration that it would "ensure that the benefits of new technologies, especially information and communication technologies [...] would be available to all" [10]. The computer is one of the main means to use ICT, but it is far from being used equally between countries and social groups. One social group, which uses the computer to a much smaller extent than the rest of the society, are older adults $[8,31]$. There has been a wealth of research about computer usage of older adults [29], but so far, this age groups' computer usage has not yet been investigated with the technology acceptance model (TAM) [7] or derivatives thereof.

\subsection{Reasons of older adults for using or not using $a$ computer}

In industrialized countries, where computer usage is not predominantly defined by economic factors, age is one of the main determinants for the digital divide, the unequal access to information technology $[6,23,25]$.

As the number of older adults using computers grows [25], the digital divide with regard to age seems to close with time. This seems to be supported by the idea of technology-generations [19] where every age cohort belongs to a certain technologygeneration, which is defined by the technology present when people are in their twenties. The cohort which is about 20 years old by the time a new technology is invented is the first one to explore the new technology. The other cohorts follow with decreasing frequency, the older they are [19]. People who are now in their twenties might still use computers once they are old. But technical innovations follow each other with high frequency, and each innovation creates another cycle with its own generation gap [22].

Additionally, access to a certain technology unfolds on several levels. Van Dijk [26] proposed a model with four consecutive kinds of access. First, there has to be the motivation to use the technology, followed by the acquisition of the material needed. On the third level, usage skills have to be adopted, and finally time has to be spent and usage diversity established [26].

\footnotetext{
${ }^{*}$ Corresponding author. E-mail: S.Naegle@uni-kassel.de. Tel: +49 561804 3467. Fax: +49 5618043542
} 
On every access level, there is a gap apparent between older adults and the majority.

\subsubsection{Motivational access}

As most people over the age of 60 have retired and job requirements no longer play a role, what are the reasons to use a computer? In a qualitative study with 35 individuals aged over 60 years, Selwyn explored reasons for computer usage as well as the social organization of usage [20]. The most important factors he found were the desire to stay up-to-date. Another reason was the help computers can offer with maintaining independence, even in case of physical immobility. A third reason was the influence of family members who wanted their older relatives to use a computer [20], a desire which is often supported with help in handling and maintenance $[15,20]$.

\subsubsection{Material or physical access}

Economic factors play an important role in the rejection of computer technology [6,27,31]. With declining income after retirement, the cost of purchasing a computer becomes more important. Therefore, it is interesting that older adults, and especially older women, often inherit old hardware from younger family members $[15,20]$.

\subsubsection{Skill access}

As computers didn't play a role in most older adults' working life, many of them start as novices at an old age. They need more help during acquisition of computer skills, more time to complete tasks, and make more errors than younger adults [25]. Almost all older adults receive help dealing with the computer, mainly from younger family members [15]. The older the users are, the more they also use this support to acquire new skills [15].

\subsubsection{Usage access}

Some applications are used in equal numbers, for instance email or searching travel information, while others such as social networking, scanning, or printing show an age dependency with lesser use by older adults [15,27,31]. Czaja [5] found age to be the strongest predictor of breadth and diversity of computer usage. The connection between old age and the smaller number of applications used is also evident in big demographic surveys $[6,27,31]$.

\subsection{Technology acceptance}

Different technology acceptance models have been applied for different types of technology, e,g, internet usage [12,16], mobile phone usage [4], PDA usage [30], acceptance of e-health websites [2], or acceptance of health care robots [11]. The technology acceptance model (TAM) [7] has been used to study computer usage in a business context [13], but so far neither the technology acceptance model nor any of its derivatives have yet been used to draw conclusions based on the importance of its measures on older adults' computer usage.

\subsection{UTAUT}

To investigate the influence of the various aspects on older adults' computer usage, the Unified Theory of Acceptance and Usage of Technology (UTAUT) [28] was applied (see Figure 1).

UTAUT is a meta-model which combines elements of eight different acceptance models into four core determinants of behavioral intention (BI) and usage: performance expectancy (PE), effort expectancy (EE), social influences (SI) and facilitating conditions (FC). Each of the key constructs is operationalized through four items. The model also includes four moderating variables: age, gender, experience, and voluntariness of use. UTAUT was found to explain up to $70 \%$ of the variance in usage intention, a higher value than the underlying acceptance models have been able to explain [28].

UTAUT covers the important aspects of computer usage of older adults: the dependency on age and gender, the voluntariness of usage, as well as help and support from the social network.

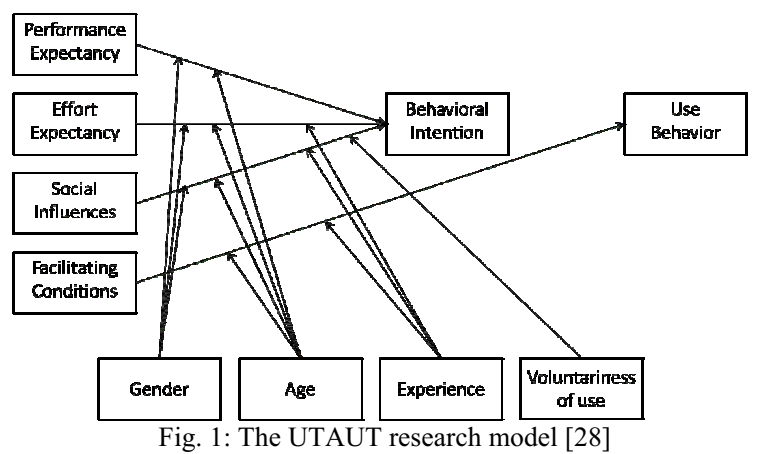




\subsubsection{Performance Expectancy (PE)}

Performance expectancy is defined as "the degree to which an individual believes that using the system will help him or her to attain gains in job performance." The 4 items are derived from the technology acceptance theory [7], the innovation diffusion theory [18] and the social cognitive theory [3].

This construct is predictive of intention, in mandatory as well as in voluntary settings $[7,28]$. The influence of the gender and age dependent variables self efficacy and anxiety [5] were found to be fully mediated by effort expectancy [28].

\subsubsection{Effort expectancy (EE)}

The items of effort expectancy, defined as "the degree of ease associated with the use of the system" are taken from perceived ease of use of both the technology acceptance model [7] and the innovation diffusion theory [13]. The construct has been shown to be a determinator of intention in voluntary settings, [4], with a stronger influence in the early stages of usage [28].

\subsubsection{Social influence (SI)}

Social influence, defined as "the degree to which an individual perceives that important others believe he or she should use the new system" is derived from subjective norm of the theory of reasoned action [9] and from social factors from Model of PC Utilization (MPCU) [24]. They touch "the individual's internalization of the reference groups' subjective culture, and specific interpersonal agreements that the individual has made with others in specific social situations". While SI was not found to be predictive for a voluntary setting in a working environment [28], it was found it to be predictive for older adults' mobile phone usage [4].

Computer usage of older adults is influenced by their social environment, with younger family members often serving as a reason to acquire a computer [20].

\subsubsection{Facilitating conditions (FC)}

Facilitating conditions are defined as "the degree to which an individual believes that an organizational and technical infrastructure exists to support use of the system". Its first three items are derived from perceived behavioral control from the theory of planned behavior (TPB), which is defined as "the ease or difficulty of performing the behavior of interest" [1]. The items cover the resources and knowledge necessary to use the system, as well as the compatibility of the new system with other systems. The last item, derived from facilitating conditions of the model of pc utilization (MPCU) [24] means that "by training users and assisting them when they encounter difficulties, some of the potential barriers to use are reduced or eliminated". This item covers the aspect of help that older adults receive from their social group as close family members often support usage through help and the donation of computer systems [15]. FC was found to be age-dependent and more predictive for older people in mandatory settings [28].

\subsubsection{Gender}

Gender differences in computer usage increase with age [21]. In Europe, about twice the number of men than women above age 55 use a computer [21].

\subsubsection{Age}

Age is an important variable for computer usage as older adults use computers less often than younger adults [8,27,31]. Further, it was found to be the strongest predictor for diversity and breadth of computer usage [5].

\subsubsection{Experience}

Experience is a combination of the length of usage time, knowledge, and the diversity or breadth of usage. Czaja [5] found breadth of computer usage to depend on age.

\subsubsection{Voluntariness of use}

Computer usage of retired people can be considered as being voluntary in the sense that there is no vocational necessity. In industrialized countries, there are more and more activities handled digitally, like for example ATMs or kiosks to buy train tickets, but until now, there has always been an analogue alternative.

\subsubsection{Behavioral Intention (BI)}

According to all technology acceptance models, behavioral intention has a direct effect on usage.

\subsection{Hypotheses}

Based on the body of aforementioned research, eight hypotheses were formulated.

H1: Performance expectancy is hypothesized to correlate with intention.

$\mathrm{H} 2$ : Effort expectancy is expected to correlate with intention. 
H3: Social influence is expected to correlate with intention.

H4: Facilitating conditions are hypothesized to correlate with use.

H5: Intention is expected to correlate with age.

H6: Age is expected to correlate with the number of applications used.

H7: Gender is expected to correlate with effort expectancy.

H8: Gender is expected to correlate with intention.

\section{Method}

\subsection{Questionnaire}

The questions included the UTAUT questionnaire on a five-point Likert scale as well as demographic information and questions about computer usage.

The UTAUT questionnaire is tailored to vocational settings and had to be transformed to cover private computer usage.

In performance expectancy, the word "job" was replaced with "interests and hobbies". The chances of getting a raise were replaced with whether using the computer would be fun and keep the interviewee cognitively fit.

Effort expectancy was kept in its original form.

In social influences, "important people" and "the management" was replaced with family and friends, "the organization" was replaced by "social environment".

Facilitating conditions were specified for the computer, such as enough money, space, and a fast internet connection. The compatibility aspect was transformed into the help available to purchase the computer and its devices.

Gender was a coded as binary variable, age as the reported age.

The applications used were measured through a 16-item-list of applications and hardware usage (e.g. email, social networks, word processor, games, installation of new software, reading news online, printer, and scanner). A composite score was obtained by summing up the responses.

Voluntariness was taken as given.

\subsection{Participants}

A total of 62 telephone interviews were conducted with the age of the participants ranging from 50 to 108 (!) years. 8 interviews were used as preliminary tests, 2 interviews were aborted.
The final interviews were conducted with 52 adults ( 25 men, 27 women), age ranging from 50 to 90 years $(\mathrm{M}=70.02$ years, $\mathrm{SD}=10.06$ years $)$. Participants were recruited in 4 age groups, covering the decades from 50-59, 60-69, 70-79 and 80+ years, with each group divided into users and non-users (see Table 1). The connections were made through private contacts, a computer class at a community college and a residential home. The interviews were conducted in spring 2010. All participants lived in Germany, 4 had an immigration background. 48 participants were community-dwelling, and 4 lived in a residential home. The whole sample is described in Table 1.

Given the way of recruiting and the number of participants, the sample is not representative. However, to draw conclusions from the results, the sample was compared with the rest of the German society and was found to match important factors. The income and household size of the participants was as expected for this age group. The users interviewed were slightly better educated than average, whereas nonusers resembled average education for this age group. The higher education of users reflects the correlation between education and computer usage, as education is a predictor thereof [5]. The sample included 35 users and 17 non-users. It was not possible to recruit non-users below the age of 60 and only few below 70 . Most users had more than 5 years of experience (89\%). Microsoft Windows was the predominantly used operating system (83\%), followed by Linux $(9 \%)$ and MacOS (3\%). Given the Microsoft market share of $95 \%$ [17], this is unusually diverse. The interviews, which contained more questions than presented in this article, took between 10 and 27 minutes for users and between 8 and 19 minutes for non-users.

\section{Results}

The reliability of the UTAUT measures was calculated. The Cronbachs $\alpha$ was acceptable for performance expectancy (0.70) and effort expectancy (0.81) and low for social influence (0.66) and facilitating conditions (0.54).

Means of the UTAUT constructs were all above the standard mean: $3.61-4.28$ as opposed to 2.5 on a five-point scale. The sum of the self-reported number of applications used ranged between 2 and 14 $(\mathrm{M}=8.54, \mathrm{SD}=3.42$. Spearman's $\rho$ correlations were calculated between the factors (see Table 2). 
H1 was accepted: A significant correlation was found between performance expectancy and behavioral intention. This supports the idea that older adults only use the computer if they perceive it as valuable for their everyday life. For instance, it allows them to be quicker with tasks they have to do anyway or if they can do things they value and would not be able to do otherwise.

H2 had to be rejected: Interestingly effort expectancy did not significantly correlate with behavioral intention. The gender difference was significant, and most pronounced for female non-users, but for no group were the correlations with intention significant.

H3 could be accepted: Social influence correlated significantly with behavioral intention. This correlation was stronger for women and not significant for men. A supporting social group and computer usage go hand in hand, especially for women.

H4 could be accepted: Facilitating conditions correlated with use. Enough resources, help, and the knowledge to use the system correspond with higher usage.

H5 had to be rejected: The older adults get, the less likely they are to use a computer. However, age did not correlate with intention. The non-significance is probably attributed to the design of the study with about the same amount of users in each age group and BI significantly correlating with use.

H6 could be accepted: A significant negative correlation was found between age and the number of applications used on the computer. This correlation was stronger for men and non-significant for women. The participants under the age of 60 used an average of 11 applications, the older participants used only an average of between 7 and 8 applications. One reason for this effect might be the necessity of using more applications in the working environment than in retirement.

H7 was accepted: A significant correlation was found between effort expectancy and gender. Lower self-efficacy and higher computer anxiety seem to match lower effort expectancy. ${ }^{1}$

H8 had to be rejected: Even though women are much less likely to use a computer, in this study BI did not correlate with gender. Men showed slightly lower mean BI but that was far from being significant. This effect might be caused by the design of the study with equal numbers of male and female users and non-users respectively.

For an overview over all hypotheses see Table 3.

\footnotetext{
${ }^{1}$ Higher scores in effort expectancy mean that the interface is easier to use even though the name suggests otherwise.
}

\section{Discussion}

The results of this study show that older adults' computer acceptance is mainly driven by facilitating conditions and expected performance gains, with facilitating conditions being even more important than the performance expectancy.

The importance of performance expectancy is analogue to the original UTAUT and most other acceptance studies. The importance of facilitating conditions for use, especially for older adults with a long time of experience is also found in the original model. The strong correlation of facilitating conditions with the intention to use a computer is surprising, as in the original studies this influence vanished after a period of use [28]. The reason for the correlation between facilitating conditions and intention might be the importance of the social support system. Facilitating conditions cover aspects of perceived behavioral control (TPB) and facilitating conditions (MPCU), operationalized through the technical infrastructure, knowledge, and human help available. Older adults often receive used computer systems, or use their helpers to learn how to use the computer [15], both of which are aspects fostering intention.

Another interesting result is the missing correlation between the expected effort and the intention to use a computer. For the participating users, with most of them having more than 5 years of experience, this result can be explained with the findings of Venkatesh, that effort predicts intention mainly in the early stages of usage, and becomes "non-significant over periods of extended and sustained usage" [28]. Yet this finding does not explain why effort expectancy and intention did not correlate for non-users, either. One reason might be that computers are not a "new" technology. Even non-users have seen screen shots, or other people interacting with computers, and have gained a mental model of their functionality and the necessary interactions, as limited as this model might be. Another aspect could be the findings of Melenhorst [14] that technology adoption of older adults seems to focus more on benefits than on costs, rendering effort less important.

\section{Conclusion}

Older adults' computer usage is mainly influenced by expected performance gains and facilitating conditions. While there is some influence of the social 
environment, the expected effort does not play a significant role.

One lesson, which can be learned from the strong connection between the perceived performance gains and the intention to use a computer, is to accept the fact that older adults might simply not perceive a computer to be a valuable tool to fulfill their life's goals. That means on the other hand that, once older adults consider the computer to be valuable, they will be motivated to use it. This result highlights the importance to carefully explore the users' needs and wants. The system should be designed so that new and useful features can easily be added and unnecessary features can easily be removed.

Because of the low internal consistency of facilitating conditions in this study, it is difficult to draw conclusions from its importance on both, intention and usage. The underlying cause for this result, and possible implications thereof should be investigated in the future. With the high correlation taken as a given, inferences can be made from the underlying concepts of self-efficacy and assistance. The system should be inexpensive, it should evoke the impres- sion to be easily mastered, and foster immediate support in case of difficulties. Its interactions should be intuitive and consistent, its appearance attractive, and cooperation with family and friends should be made as easy as possible, especially if the parties are spatially separated.

\section{Limitations}

The sample of participants for the study was arbitrarily recruited in Germany and consists of a relatively small number of 52 participants. Even though it resembles several demographic factors for this age group, it is not representative.

The reliability measures for facilitating conditions (0.54) and social influences (0.66) were low, so that the results drawn from these constructs must be handled with caution. The items should revised, and further work should be put into the adaptation and validation of the questionnaire.

Table 1

Sample description.

\begin{tabular}{|c|c|c|c|c|c|c|c|c|c|}
\hline \multirow[b]{3}{*}{ Number } & \multirow[t]{2}{*}{ Total } & \multicolumn{4}{|c|}{ Age group } & \multirow[t]{2}{*}{ Men } & \multirow[t]{2}{*}{ Women } & \multirow[t]{2}{*}{ Users } & \multirow[t]{2}{*}{ Non-users } \\
\hline & & $\begin{array}{l}50-59 \\
\text { years }\end{array}$ & $\begin{array}{l}60-69 \\
\text { years }\end{array}$ & $\begin{array}{l}70-79 \\
\text { years }\end{array}$ & $\begin{array}{l}80+ \\
\text { years }\end{array}$ & & & & \\
\hline & 52 & 10 & 14 & 10 & 6 & 25 & 27 & 35 & 17 \\
\hline $\begin{array}{l}\text { Usage (Users, } \\
\text { Non-users) }\end{array}$ & 35,17 & 9,0 & 10,4 & 10,9 & 6,4 & 18,17 & 7,10 & - & - \\
\hline Age (M, SD) & $\begin{array}{l}70.02 \\
10.06\end{array}$ & $54.2,2.4$ & $65.8,2.6$ & $72.9,2.6$ & $84.7,3.3$ & $70.0,10.5$ & $70.0,9.9$ & $68.2,10.7$ & $73.9,7.4$ \\
\hline $\begin{array}{l}\text { Gender (men, } \\
\text { women) }\end{array}$ & 25,27 & 5,5 & 6,8 & 9,10 & 5,5 & - & - & 18,17 & 7,10 \\
\hline PE (M, SD) & $4.3,0.7$ & $4.5,0.4$ & $4.3,0.7$ & $4.3,0.8$ & $4.1,1.0$ & $4.4,0.9$ & $4.1,0.8$ & $4.6,0.4$ & $3.7,0.9$ \\
\hline $\mathrm{EE}(\mathrm{M}, \mathrm{SD})$ & $3.7,0.9$ & $3.8,1.2$ & $3.3,1.0$ & $3.7,0.8$ & $4.0,0.5$ & $4.1,0.7$ & $3.3,0.9$ & $3.8,0.9$ & $3.3,0.9$ \\
\hline SI (M, SD) & $3.6,0.9$ & $3.6,0.7$ & $3.8,0.9$ & $3.8,0.9$ & $3.1,1.1$ & $3.6,0.8$ & $3.6,1.1$ & $3.8,0.9$ & $3.1,0.9$ \\
\hline $\mathrm{FC}(\mathrm{M}, \mathrm{SD})$ & $4.2,0.9$ & $4.7,0.4$ & $3.8,1.0$ & $4.1,0.8$ & $4.2,0.9$ & $4.3,0.7$ & $4.0,1.0$ & $4.5,0.7$ & $3.4,0.7$ \\
\hline $\mathrm{BI}(\mathrm{M}, \mathrm{SD})$ & $3.4,1.7$ & $3.8,0.0$ & $3.3,1.1$ & $2.5,1.4$ & $2.6,1.5$ & $3.1,1.2$ & $2.8,1.3$ & $3.7,0.1$ & $1.2,0.7$ \\
\hline $\begin{array}{l}\text { NA, users only } \\
(\mathrm{M}, \mathrm{SD})\end{array}$ & $8.5,3.4$ & $11.1,1.6$ & $7.9,4.5$ & $7.8,2.6$ & $7.0,3.0$ & $9.3,3.8$ & $7.8,2.9$ & $8.5,3.4$ & - \\
\hline
\end{tabular}

Note: PE: Performance expectancy, EE: Effort expectancy, SI: Social influence, FC: Facilitating conditions, BI: Behavioral intention, NA: Number of applications used. 
Table 2

Spearman's correlations between constructs $[\mathrm{n}=52]$

\begin{tabular}{|c|c|c|c|c|c|c|c|c|}
\hline & $\mathrm{EE}$ & SI & $\mathrm{FC}$ & Gender & Age & $\begin{array}{l}\mathrm{NA}, \\
\mathrm{N}=35\end{array}$ & BI & Use \\
\hline PE & 0.22 & $0.30 *$ & $0.33 *$ & -0.17 & -0.02 & 0.08 & $0.54 * * *$ & $0.48 * * *$ \\
\hline $\mathrm{m}[\mathrm{n}=25]$ & 0.28 & -0.03 & 0.25 & - & 0.10 & -0.13 & $0.58 * *$ & $0.56 * *$ \\
\hline $\mathrm{w}[\mathrm{n}=27]$ & 0.02 & $0.55 * *$ & 0.33 & - & -0.14 & 0.30 & $0.49 * *$ & $0.39 *$ \\
\hline $\begin{array}{l}\text { Users } \\
{[\mathrm{n}=35]}\end{array}$ & 0.21 & 0.08 & 0.24 & -0.21 & $0.35 *$ & 0.08 & 0.04 & - \\
\hline $\begin{array}{l}\text { Non-users } \\
{[\mathrm{n}=17]}\end{array}$ & -0.05 & 0.30 & -0.01 & -0.15 & -0.29 & - & $0.64 * *$ & - \\
\hline $\mathrm{EE}$ & & 0.10 & 0.27 & $-0.45 * *$ & 0.09 & 0.34 & 0.27 & 0.26 \\
\hline M & & -0.09 & -0.05 & - & -0.28 & $0.53 *$ & 0.15 & 0.14 \\
\hline W & & 0.10 & $0.47 *$ & - & $0.44 *$ & -0.01 & 0.31 & 0.37 \\
\hline Users & & 0.04 & 0.08 & $-0.34 *$ & 0.02 & 0.34 & 0.06 & - \\
\hline Non-users & & -0.07 & 0.22 & $-0.72 * *$ & $0.58 *$ & - & 0.03 & - \\
\hline SI & & & $0.30 *$ & 0.01 & -0.07 & -0.16 & $0.37 * *$ & $0.35 *$ \\
\hline M & & & 0.28 & - & -0.27 & -0.25 & 0.31 & 0.34 \\
\hline W & & & 0.33 & - & 0.08 & -0.08 & $0.42 *$ & 0.36 \\
\hline $\mathrm{FC}$ & & & & -0.20 & 0.02 & 0.26 & $0.58 * * *$ & $0.58 * * *$ \\
\hline M & & & & - & 0.06 & 0.04 & $0.43^{*}$ & $0.46^{*}$ \\
\hline W & & & & - & -0.02 & $0.60 *$ & $0.67 * * *$ & $0.64 * * *$ \\
\hline Gender & & & & & -0.03 & -0.20 & -0.13 & -0.10 \\
\hline Age & & & & & & $-0.50 * *$ & -0.26 & -0.27 \\
\hline M & & & & - & & $-0.69 * *$ & -0.32 & -0.31 \\
\hline W & & & & - & & -0.27 & -0.25 & -0.24 \\
\hline NA, Users & & & & & & & 0.25 & - \\
\hline $\mathrm{BI}$ & & & & & & & & $0.96 * * *$ \\
\hline
\end{tabular}

Notes: 1: Significance levels: $*: \mathrm{p}<0.05, * *: \mathrm{p}<0.01,{ }^{*} * * \mathrm{p}<0.001$.

2: PE: Performance expectancy, EE: Effort expectancy, SI: Social influence, FC: Facilitating conditions, BI: Behavioral intention, NA: Number of applications used.

Table 3

Hypotheses

\begin{tabular}{lll} 
Hypothesis & Correlation & Result \\
\hline H1: Performance expectancy (PE) correlates with intention (BI) & $0.54^{* * *}$ Accepted & 0.27 \\
H2: Effort expectancy (EE) correlates with intention (BI) & $0.37^{* *}$ & $0.58^{* * *}$ \\
H3: Social influence (SI) correlates with intention (BI) & -0.26 & Accepted \\
H4: Facilitating conditions (FC) correlates with use & $-0.50^{* *}$ & Accepted \\
H5: Behavioral intention (BI) correlates with age & $-0.45^{* *}$ & Accepted \\
H6: The number of applications used (NA) correlate with age & -0.13 \\
H7: Effort expectancy (EE) correlates with gender & Accepted \\
H8: Behavioral intention (BI) correlates with gender & Rejected
\end{tabular}




\section{References}

[1] I. Ajzen, The Theory of Planned Behavior, Organizational Behavior and Human Decision Processes 50 (1991), 179-21.

[2] K. Arning and M. Ziefle, Different Perspectives on Technology Acceptance: The Role of Technology Type and Age, in: USAB 2009, LNCS 5889, A. Holzinger and K. Miesenberger, eds., Springer, Berlin, 2009, pp. 20-41.

[3] D. Compeau and C.A. Higgins, Computer Self-Efficacy: Development of a Measure and Initial Test, MIS Quarterly 19 (1995), 189-211.

[4] M. Conci, F. Pianesi, and M. Zancanaro, Useful, social and enjoyable: mobile phone adoption by older people, in: Human Computer Interaction, Interact 2009, Part 1, LNCS 5726 , T. Gross, et al., eds, Springer, Berlin, 2009, pp 63-76.

[5] S.J. Czaja, N. Charness, A.D. Fisk, C. Hertzog, S.N. Nair, W.A. Rogers, and J. Sharit, Factors predicting the use of technology: findings from the Center for Research and Education on Aging and Technology Enhancement (CREATE), Psychol Aging 21 (2006), 333-352.

[6] Internet no Brasil CG, Survey on the use of information and communication technologies in Brazil 2005, Brazilian Network Information Center, nic.br, 2005.

[7] F.D. Davis, Perceived usefulness, Perceived Ease of Use, and User Acceptance of Information Technology 13 (1989), 319340.

[8] Federal Statistical Office: Statistical Yearbook 2010, Statistisches Bundesamt, Wiesbaden, 2010.

[9] M. Fishbein and I. Ajzen, Belief, Attitude, Intention, and Behavior: An Introduction to Theory and Research, AddisonWesley Pub, Reading, 1975.

[10] General Assembly of the United Nations: United Nations Millennium Declaration 55 (2000).

[11] M. Heerink, B. Kröse, V. Evers, and B. Wielanga, Assessing Acceptance of Assistive Social Agent Technology by Older Adults: the Almere Model 2 (2010), 361-375.

[12] A. Holzinger, G. Searle, and M. Wernbacher, The effect of previous exposure to technology on acceptance and its importance in usability and accessibility engineering, Univ Access Inf Soc 10 (2011), 245-260.

[13] M. Igbaria, N. Zinatelli, P. Cragg, and A.L.M. Cavaye, Personal Computing Acceptance Factors in Small Firms: A Structural Equation Model, MIS Quarterly 21 (1997), 279305.

[14] A. Melenhorst, W.A. Rogers, and D.G. Bouwhuis, Older adults' motivated choice for technological innovation: Evidence for benefit-driven selectivity, Psychology and Aging 21, (2006), 190-195.

[15] S. Nägle and L. Schmidt, Analyse der Computernutzung älterer Menschen: Einflussfaktoren und Gestaltungsbedarf, in:Mensch, Technik, Organisation - Vernetzung im Produktionsentstehungs- und -herstellungsprozess, Gesellschaft für Arbeitswissenschaft e.V., ed, GfA-Press, Dortmund, 2011, pp 515-519.

[16] S. Pan and M. Jordan-Marsh, Internet use intention and adoption among Chinese older adults: From the expanded technology acceptance model perspective, Computers in Human Behavior 26 (2010), 1111-1119.

[17] A. Roesler and B. Stiegler, eds, Microsoft: Medien, Macht, Monopol, Suhrkamp, Frankfurt/Main, Suhrkamp, 2000.

[18] E.M. Rogers, Diffusion of innovations, Free Press, New York, 1995.
[19] R. Sackmann and A. Weymann, Die Technisierung des Alltags. Generationen und technische Innovationen, Campus Verlag, Frankfurt/Main, 1994.

[20] N. Selwyn, The information aged: A qualitative study of older adults' use of information and communications technology, Journal of Aging Studies 18 (2004), 369-384.

[21] H. Seybert, Gender differences in the use of computers and the Internet. Eurostat, European Communities, Luxembourg, 2007.

[22] A. Smith, Americans and their gadgets, Pew Research Center's Internet \& American Life Project, Washington, DC, 2010.

[23] The World Internet Project Japan, Internet Usage Trends 2005: Survey Report in Japan, National Institut of Information and Communications Technology, Tokio, 2005.

[24] R.L. Thompson, C.A. Higgins, and J.M. Howell, Personal Computing: Toward a Conceptual Model of Utilization, MIS Quarterly 15 (1991), 125-143.

[25] United Nations. Economic Commission for Europe. Statistical Division, UNECE countries in figures 2009, United Nations Publication, Portland, OR, 2009.

[26] J.A.G.M. van Dijk, The Deepening Divide: Inequality in the Information Society, Sage Pub, Thousand Oaks, CA, 2005.

[27] B. van Eimeren, B. Frees, Ergebnisse der ARD/ZDFOnlinestudie 2011: Drei von vier Deutschen im Netz - ein Ende des digitalen Grabens in Sicht?, media perspektiven 7 (2011), 334-349.

[28] V. Venkatesh, M.G. Morris, G.B. Davis, F.D. Davis, User Acceptance of Information Technology Toward a Unified View, MIS Quarterly 27 (2003), 425-478.

[29] N.L. Wagner, K. Hassanein, M.M. Head, Computer use by older adults: A multi-disciplinary review, Computers in $\mathrm{Hu}-$ man Behavior 26 (2010), 870-882.

[30] W. Wilkowska and M. Ziefle, Which factors form older adults acceptance of mobile information and communication technologies?, in: USAB 2009, LNCS 5889, A. Holzinger and K. Miesenberger, eds., Springer, Berlin, 2009, pp 81101

[31] K. Zickuhr, Generations 2010, Pew Research Center's Internet \& American Life Project, Washington, DC, 2010 